\title{
Discordias y solidaridades: \\ los preceptores de primeras \\ letras en Puebla (1820-1860)
}

Discords and Solidarities: Elementary

School Teachers in Puebla (1820-1860)

\author{
Mariana Marín Ibarra \\ Universidad Autónoma de Tlaxcala \\ clasedeetica@hotmail.com
}

\begin{abstract}
Resumen
La creación de la escuela pública mexicana, a partir de la era independiente, requirió la participación de los preceptores de primeras letras quienes se encargarían de forjar a los nuevos ciudadanos mexicanos. La presente investigación indaga cómo actuaron los preceptores en las escuelas públicas sufragadas por el Ayuntamiento de la ciudad de Puebla después de que se disolvió su gremio, en un estado que brindó ciertas facilidades y tímida infraestructura para la educación. Se muestra la serie de tensiones que tuvieron lugar entre el Ayuntamiento y los mismos preceptores durante varias décadas del siglo XIX, tensiones que llevaron al grupo a construir solidaridades, especialmente en coyunturas adversas como la intervención norteamericana y los embates estructurales de las Leyes de Reforma.
\end{abstract}

Palabras clave: preceptores, Ayuntamiento, Puebla, primeras letras

\section{Abstract}

The creation of the Mexican public school in the independence era required the participation of the teachers in charge of the formation of the new citizens. This article explores the performance of teachers in the schools run by the municipality of the city of Puebla after the formal dissolution of their corporation, within a state which provided some facilities and a weak infrastructure for public education. The article shows the tensions between the Puebla municipality and the teachers throughout several decades of the nineteenth century, a period during which the teachers developed a number of solidarities, especially in adverse situations such as the North-American Invasion and the structural changes brought about by the liberal Reform Laws.

Keywords: teachers, municipality, Puebla, elementary schools. 


\section{Introducción}

La investigación sobre la historia de la educación se ha abordado desde distintos ámbitos, pero es necesario mencionar que a partir de los años setenta del siglo Xx los estudiosos movieron el lente de enfoque de una historia que vislumbra los acontecimientos a otra que coloca el centro de atención en la importancia de las estructuras, aunque posteriormente se optó por atender una historia "cuyo interés mayor es el estudio, plural y diverso de los procesos pedagógicos y educativos. El trabajo historiográfico, en consecuencia, se desplazó de las estructuras a los actores" (Márquez, 2004: 30).

Atendiendo entonces a las nuevas propuestas, la presente investigación visibiliza a los actores del proceso educativo. Particularmente a los preceptores de primeras letras que vivieron y laboraron en la ciudad de Puebla durante la primera mitad del siglo XIX. Asimismo se rescatan los nombres de los preceptores y preceptoras de primeras letras, así como los mecanismos de selección implementados por el Cabildo Angelopolitano y la Junta de Caridad para el desarrollo de la enseñanza pública; se analizan los elementos de poder existentes en dicho proceso en el que se observan las fuerzas que mediaron entre los miembros del Ayuntamiento y el clero, instituciones formadoras del conocimiento de primeras letras.

Es de vital importancia señalar que a lo largo del presente artículo los términos maestro(a) y preceptor(a) se usarán de manera indistinta debido a que en las fuentes de archivo así aparecen. En los documentos consultados, tanto el Ayuntamiento como las escuelas o los visitadores hicieron uso indiscriminado de dichos términos sin aludir a una diferencia entre ellos, práctica que se observa constantemente durante todo el periodo de estudio que aquí presentamos.

A continuación se listan los cuatro apartados que componen este artículo. El primero es referente a los antecedentes generales de la investigación de la historia de la educación en México que enmarca el periodo 1820-1860; posteriormente, se establecen los antecedentes novohispanos que muestran la formación del gremio de preceptores poblanos; en el tercer apartado se alude a la importancia que tuvo la invasión norteamericana la cual afectó el óptimo desenvolvimiento de la escuela pública en la ciudad angélica, particularmente en la labor de los maestros; y, finalmente, se establece el cisma que generaron las Leyes de Reforma al favorecer el proceso de secularización de la educación. Se profundiza, especialmente, en el rescate de nombres y fragmentos de la trayectoria académica de los preceptores y se destaca la interesante labor de la familia Bermúdez. 


\section{Estado del arte}

El Consejo Mexicano de Investigación Educativa (COMIE) ha dado pasos significativos en materia de historia al haber creado en años anteriores una serie de libros sobre las investigaciones educativas existentes en México. Entre sus publicaciones más recientes se encuentra la colección La Investigación Educativa en México (1999-2002)(2003), que se encarga de compilar balances historiográficos en torno a los trabajos hallados de las etapas colonial, decimonónica y del siglo xx.

Los autores brindan diversas fuentes de investigación para la historia debido a que se encargan de enumerar una amplia bibliografía concerniente a distintos momentos cronológicos. De igual forma crean un diccionario que establece conceptos y bases teórico-metodológicas que ayudan a la investigación de la historia educativa; promueven un listado de tesis de licenciatura y posgrado que mencionan los aportes que se han hecho en la República Mexicana, dejando en claro la riqueza del trabajo colaborativo y la necesidad de formar redes de investigación que permitan generar, unir y fomentar la investigación regional.

Es importante reconocer la enorme labor de las redes de investigación educativa. puesto que sólo de esa forma se conocen las valiosas aportaciones regionales a la historia de la nación, reconstruyendo fragmentos de un rompecabezas que se arma a través de investigaciones serias, profundas y relevantes. Así, las propuestas del COMIE brindan un camino certero respecto a los estudios históricos de la educación y puntualizan en la necesidad de debatir acerca de la feminización del magisterio a través de diversas ópticas. Si bien se ha mencionado a las mujeres en la historia su participación ha pasado desapercibida como sujetos susceptibles de ser analizados desde una perspectiva de género y no como parte de un todo institucional, pues dentro de lo global se desdibujan las relaciones de poder informales existentes en las relaciones sociales.

Los trabajos pioneros de Dorothy Tanck de Estrada y Anne Staples sobre la educación decimonónica han sido referencia obligada para los estudios educativos, pues sus aportes generales y particulares dan luz a la historia de la educación mexicana. Una excelente compilación de artículos al respecto la tenemos en el libro Historia mínima ilustrada de la educación en México (Tanck de Estrada, 2011), editado por El Colegio de México y en el que ambas autoras participan con sus análisis sobre el sistema educativo, desde la legislación, la pedagogía y la vida cotidiana de la escuela elemental y los estudios superiores.

El amplio estudio de Tanck muestra los avances y particularidades del entramado educativo a partir de la capital virreinal; desentraña los acontecimientos desde finales del siglo XVIII, la política de las Cortes de Cádiz y la importancia del castellano como lengua oficial desplazando al latín, sólo por mencionar algunos aspectos. En la sección del México independiente evidencia los progresos y permanencias y, sobre todo, desmitifica el monopolio 
educativo de la institución eclesiástica al mencionar los diversos cuerpos creados para el desarrollo institucional político-económico de un Estado más moderno que no pudo frenar la vorágine proveniente de las ideas ilustradas. La concepción ideológica de varios siglos no pudo eliminarse de tajo, de tal manera que en el siglo posterior se verá una clara combinación entre la educación tradicional virreinal y los aportes ilustrados, sin embargo, no se profundiza en la participación del profesorado en la construcción del complejo entramado educativo.

Anne Staples, en su artículo "El entusiasmo por la independencia" (Tanck de Estrada, 2011: 149-188), muestra los grandes paradigmas educativos establecidos a partir de la creación del México independiente. El imaginario político promovió la cultura de la culpabilidad hacia los españoles como responsables del gran atraso del país tras siglos de dominación. Surgieron entonces figuras políticas, escritores y religiosos ansiosos de terminar con el analfabetismo. Sin embargo, dichas figuras se enfrentaron a la realidad mexicana basada en la diversidad cultural, diferencias rurales y urbanas, los indígenas, la inexistencia de carreras técnicas que la modernidad demandaba y la necesidad apremiante de formar ciudadanos con un territorio económicamente quebrado tras la Guerra de Independencia. Por tanto, el trabajo de Staples resalta esas discrepancias culturales y no se enfoca al ámbito citadino como es el objetivo de la presente investigación.

La reconstrucción histórica que se refiere a la participación de los maestros como actores importantes del sistema educativo, regularmente se disuelve ante la presentación de un marco contextual o la vida en el aula dejando de lado el rescate de su biografía, los mecanismos de poder a los que se enfrentaron e incluso sensibilidades ante un presente adverso.

Los estudios realizados para el caso poblano reconstruyen la historia de la educación a partir de las bases mencionadas. Así, podemos referirnos a Estela Munguía Escamilla (2010) quien en una investigación de largo aliento rescata el contexto histórico-social; o a la perspectiva institucional en la tesis de Mónica Alejandra Rosales Salazar (2008) sobre la Junta Patriótica; o al trabajo de Lourdes Herrera Feria sobre el Hospicio de Pobres (2015). A partir de este último se desprende una serie de investigaciones que rescatan una infancia asilada y el papel de las comadronas y maestras de los menesterosos (2012a). Así también se brinda un panorama general de la instrucción pública en Puebla durante el siglo XIX en el que se atiende el número de escuelas y alumnos reconocidos por el Ayuntamiento (2012b); la mirada de la infancia desamparada.

El rescate histórico de la educación poblana también se dio a manos de Jesús Márquez Carrillo en cuyo libro, La obscura llama, élites letradas, política y educación en Puebla 1750-1835 (2012), reconstruye el escenario social, político y educativo de la ciudad de Puebla desde el último tercio del virreinato hasta los años treinta del siglo XIX con el establecimiento en México del liberalismo y la llustración, corrientes que afectaron significativamente la práctica 
educativa al promover la creación de un aparato público cívico que se encargaría de establecer nuevas formas de control social.

Es a partir de los aportes de Herrera, Márquez y Torres que se puede crear una línea que brinde continuidad a la historia de la educación poblana, puesto que la presente investigación indaga sobre un periodo escasamente estudiado debido a las constantes batallas y los cambios de gobierno. Se rescatan las vicisitudes político-sociales a las que se enfrentaron los preceptores al crear alianzas que favorecieron el desarrollo de su práctica y que, de acuerdo con su relación con las prácticas del poder ejercidas por la Iglesia y el Estado, se enraizaron en la sociedad logrando ejercer el arte de las letras, pero siempre amparados en la política pública y en estrategias sociales, mecanismos indispensables para tener éxito.

Es fundamental salvar esbozos de biografías que ayuden al historiador a desentrañar los lazos y solidaridades familiares o amistades que forjaron las redes del grupo de preceptores de primeras letras; entrelazar la vida pública con su participación pública debido a que, finalmente, fueron estas personas quienes forjaron los criterios de cientificidad creados por el Estado y de los que se apropió la población mostrando la compleja vorágine en la que aún se halla inmerso el espacio educativo.

\section{Antecedentes novohispanos: el gremio de preceptores}

Una característica de la sociedad novohispana es la creación de estamentos sociales, así las relaciones entre los individuos se realizaron a través de corporaciones que trabajaron como articulaciones de un cuerpo más grande donde la cabeza era el Estado. Los maestros no fueron ajenos a dicho devenir social y crearon su corporación nombrada El Arte de Enseñar a Leer, Escribir y Contar y la Doctrina Cristiana. Para 1601 se formó el Gremio de los Maestros del Nobilísimo Arte de Primeras Letras (Rodríguez, 2014: 80). Los maestros debían ser de sangre pura, cristianos viejos, hijos legítimos y probar sus buenas costumbres logrando así que sólo los españoles pudieran formar parte. Este gremio brindó una serie de concesiones a sus miembros gracias a los postulados realizados por Enrique II y Carlos V, que les permitieron portar armas, tener esclavos con espadas y caballos de armas, además de que no podían ser encarcelados y gozaban de una distinción respecto a su arte (Tanck de Estrada, 2005: 92).

Dentro de este grupo se establecieron reglamentos internos que protegían a sus miembros de la competencia y al mismo tiempo limitaban el oficio para dar fiel seguimiento a lo estipulado en las ordenanzas, quedando así los miembros bajo la autoridad municipal. Los maestros de la ciudad de Puebla que ingresaban al gremio de primeras letras tenían que 
realizar un examen de conocimientos ante el Cabildo y sólo podían ser de nacionalidad española; incluso se aceptó a las mujeres para la escuela de las amigas y se les exigía ser españolas, presentar su fe de bautismo, pureza de sangre, una carta del párroco y debían realizar un examen, además de tener buena conducta y comprobantes de legitimidad. Entre los requisitos de los preceptores varones se les pedía saber leer romana en libros y cartas, saber escribir con letras bien formadas, se les demandaba realizar planas de letras y tener habilidades para sumar, restar, dividir, multiplicar y hacer cuentas (Rodríguez, 2014: 81-82).

Los preceptos establecidos desde la cédula del 14 de agosto de 1768, que promovían la participación de los maestros seculares en las escuelas de primeras letras hicieron mella en la Puebla novohispana donde la influencia del clero se hizo patente en el proceso de selección de preceptores. Es por ello que las preocupaciones y los consejos de los párrocos se hacían oír para eliminar a los que consideraban personas poco acreditadas para la enseñanza, como se muestra en la siguiente cita: "[...] los buenos párrocos que hoy lamentan la desgracia de tener que confiar su grey a la conducta escandalosa de un vago que se les vende por maestro de primeras letras, no por haber otro: entendiéndose entonces en la Junta de Caridad, podrían conseguir para sus escuelas unos sujetos hábiles y de recomendable conducta" (Rosales, 2008: 54). Para acceder a cualquier plaza de maestro en las escuelas públicas para varones o mujeres los preceptores debían presentar cartas de buena conducta, de preferencia acreditadas por su párroco o por alguna persona reconocida ampliamente por la sociedad como moralmente destacada.

Durante el periodo colonial se formaron las escuelas denominadas "Amiga", lugares en donde se instruía a las niñas pobres. Pero la percepción social que se generó en torno a las maestras atendía a dos discursos: el de Tomás Salgado para quien dicho arte era una "profesión a la cual se llegaba por el solo hecho de ser viejas y necesitadas", o las opiniones de León Ignacio Pico, que las definía como "ancianas ignorantísimas o fanáticas o visionarias, sin educación y sin principios, que emprenden esa carrera sólo porque no pueden mantenerse en otra" (Torres, 2014).

El ámbito masculino de la enseñanza distó mucho del femenino en la ciudad de Puebla. Mientras que las maestras no gozaban de una buena imagen frente a los letrados, al ser consideradas personas ignorantes, los preceptores lograban destacar no sólo por los exámenes públicos de sus alumnos, sino que también se hacían presentes mediante propuestas específicas que ayudaban a mejorar el sistema de enseñanza dentro de las escuelas de primeras letras. Así, en 1818, Vicente Uruanga presentó al Ayuntamiento sus "cuentas útiles, selectas y necesarias para facilitar la instrucción de la aritmética y ayudar a los padres de familia a ahorrar en la compra de libros". (Torres Domínguez, 2014: 236). Algunos planteamientos fueron tan destacados que, por ejemplo, el reglamento interno de la Escuela del 
Barrio de San Antonio se estableció como obligatorio para todas las instituciones educativas de primeras letras ubicadas en la traza urbana.

Desde el siglo XVIII las ideas ilustradas se hicieron presentes en la Nueva España y un siglo más tarde se consolidaron mostrando a los gremios como los causantes del desorden y la laxitud social, por tanto, no es de extrañarse que para 1814 se hubieran abolido los gremios, con lo cual se perdió el estricto control de las primeras letras.

Las Cortes de Cádiz fueron un referente en materia de instrucción, cabe señalar que a partir de los postulados establecidos en ellas se forjó el sistema educativo del México independiente. Así, la modernidad de la educación pública se estableció en un contexto adverso, ya que la población angelopolitana se enfrentó a crisis económicas, epidemias e intervenciones extranjeras que se fortalecieron con los sitios a la ciudad, motivados por las pugnas entre liberales y conservadores.

\section{La era de la bonanza (1820-1846)}

Los tiempos de relativa paz en la ciudad de Puebla fueron aquellos que permitieron empezar a cimentar las bases de la enseñanza pública y gratuita, es decir de 1820 a 1846. Las nuevas escuelas gratuitas fomentadas por el Ayuntamiento se amalgamaron con aquellas nacidas en el seno de la Iglesia que se ocupaban de la educación de la población menesterosa, además de conjugarse con las organizadas por los civiles como fue la Junta de Caridad, creando así una labor conjunta entre clero y Ayuntamiento para el fomento de la enseñanza gratuita.

Las ideas políticas ilustradas permearon en los ámbitos sociales y políticos de la naciente sociedad mexicana y se llevaron a cabo a partir del México independiente. Sin embargo, como menciona Francois Xavier Guerra, el modelo elegido por los políticos mexicanos no fue el más idóneo para el tipo de contexto en el que vivieron; es de destacar que eligieron un régimen "individualista cuando esta última está formada por actores colectivos; democrático, cuando el voto es meramente ficticio; ateo o agnóstico, cuando la sociedad es profundamente católica" (Guerra, 1985: 184-185).

Durante el siglo XIX se hablaba de lo necesario que era la instrucción de las masas para poder ilustrarlas, teniendo como objetivo final la felicidad individual, familiar y social. En palabras del inspector de escuelas: "Es una verdadera necesidad de la época para que puedan aprovechar los bienes y mejoras materiales, y los adelantos en todos ramos con que está brindando el siglo actual”' Con ello se hacía responsable al gobierno de emitir leyes que se

${ }^{1}$ Archivo Histórico General Municipal de Puebla (en adelante AHCMP), Sección: Expedientes, vol. 69, pp. 125v-126r. 
encargaran de lograr el bien común y la felicidad del pueblo, pues de lo contrario se puedría llegar a la ruina social.

Existió entonces un consenso respecto a la imperiosa necesidad de hacer llegar las primeras letras a los poblanos y para lograrlo se requirieron recursos económicos, ya que "si la nación se define por su educación, ésta se sustenta por los recursos que se otorguen" (Becerril, 2013: 51). Por tanto, el Ayuntamiento se encargó de sostener las escuelas mediante el establecimiento de impuestos que sufragaran las necesidades del nuevo país. El inyectar dinero de las arcas municipales tuvo como consecuencia que el aparato de escuelas públicas se articulara en torno a un eje: el Ayuntamiento como vigilante, protector y administrador.

Atendiendo al modelo sociopolítico que influenció la creación de las instituciones educativas no es de extrañarse que los actores que participaron en el proceso, en este caso los preceptores, continuaran en el siglo XIX con las arraigadas prácticas coloniales que existieron en su imaginario. La atención de corte pastoral permeó la educación pública a través de los "principios teológicos del cuidado del alma (los cuales) se revisan como elaboradas técnicas para intensificar las subjetividades a través de la autoinspección y autorrectificación" (Popkewitz, 1998:80). Dichas ideas moldearon a los futuros ciudadanos mexicanos desde las primeras letras.

El siglo XIX vio nacer y difundirse la enseñanza pública gratuita a través de las escuelas de primeras letras. El discurso de la escolarización fue el estandarte del gobierno mexicano. En ese sentido la misión era "rescatar al niño de los males morales y económicos de la industrialización, y de producir al ciudadano que participara de una sociedad democrática liberal" (Popkewitz, 1998:75). Es así que la importancia y trascendencia de los preceptores se hace patente, por lo que es necesario reconocerlos y visibilizarlos para comprender su labor educativa.

Los mecanismos de selección establecidos por el clero desde el periodo colonial siguieron vigentes después del proceso de independencia. Será una constante, a lo largo de la era decimonónica, que los preceptores deban acreditar su moralidad y religiosidad mediante cartas de recomendación elaboradas por los párrocos se trata de un primer e importante filtro para poder acceder a la enseñanza de primeras letras. Así el clero se convirtió en un aval de la enseñanza secular.

Es necesario enfatizar los mecanismos de poder existentes entre las autoridades y los preceptores, ya que mientras algunas peticiones se quedaron en espera de resolución otras fueron rápidamente contestadas por la Comisión de Escuelas. Por tanto, como menciona Francois Xavier Guerra respecto a la creación del Estado moderno:

[...] no tenía ante él (quién) más que comunidades indígenas o campesinos todavía coherentes, haciendas y enclaves señoriales, clanes familiares, redes de lazos personales 
y de clientelas, en fin, una multitud de cuerpos fuertemente jerarquizados, pequeños y grandes; uno de ellos gigantesco, la Iglesia como estamento, todavía omnipresente, vista como piedra angular de todo el antiguo edificio sociopolítico (Guerra, 1985: 11).

La relación entre clero y gobierno se hace patente en tanto que realizaban acciones conjuntas en pro de la educación de los desvalidos habitantes de Puebla. Está el caso en el que se aumentó el sueldo no de una sino de cuatro maestras que laboraron en la amiga de Nuestra Señora de los Gozos y se enfatiza que esta misma situación se dio en la escuela que llevaba la Junta de Caridad, asociación que fue ampliamente cobijada por el Ayuntamiento. Todas estas escuelas gozaron de presupuesto y facilidades para el desarrollo de la instrucción pública. Probablemente hubo lazos de poder entre los directivos de la Junta de Caridad y los de la escuela De los Gozos, puesto que ambas había miembros del clero y existía un pensamiento ampliamente influido por la Iglesia.

El cabildo poblano trató de tener conocimiento de lo ocurrido dentro del espacio escolar para lo cual delegó la tarea en visitadores que examinaban a los preceptores. Sin embargo, el dictamen no se realizaba invariablemente en cuestión de conocimientos, sino que también se revisaba la puntualidad de los maestros y los alumnos, el cumplimiento del reglamento, el carácter rudo o indulgente del docente, las doctrinas y costumbres que se practicaban dentro del aula, además de conocer los libros que se manejaban y saber si los alumnos adelantaban en su educación. ${ }^{2}$ No obstante, para este último requerimiento no se crearon parámetros que pudieran medir dicho adelanto, por tanto, la apreciación quedaba a la consideración empírica del visitador.

Mientras que para las escuelas públicas se establecieron visitas mensuales, para las particulares éstas eran bimestrales con el fin de cuidar "que no se enseñen en ellas doctrinas contrarias a la sana moral y religión, y a la constitución y forma de gobierno." ${ }^{3}$ A pesar de las buenas intenciones del Ayuntamiento se observa que la situación superó las capacidades del Estado, ya que son exiguos los informes hallados respecto al estado de la educación en Puebla los cuales se remiten exclusivamente a algunas de las escuelas públicas, por tanto, la labor de los maestros de escuelas privadas no estaba controlada como en las escuelas gratuitas, gozando así del privilegio de no ser observadas por el gobierno.

El nombre y la palabra de las mujeres que serían las nuevas preceptoras quedan invisibilizados tras la voz del padre o el esposo quienes hablaban por ellas ante el Ayuntamiento, logrando acuerdos válidos y exitosos. Sin embargo, es importante reconocer que la participación de las mujeres en la esfera pública fue significativa, pues en el caso de las preceptoras de primeras letras encontrarse al servicio del Ayuntamiento de Puebla las convirtió en sujetos

\footnotetext{
${ }^{2}$ AHGMP, Sección: Expedientes, vol. 69, f. 142v.

${ }^{3}$ AHGMP, Sección: Expedientes, vol. 69, f. 144r.
} 
dignos de reconocimiento por la ardua labor en la formación de los nuevos ciudadanos, útiles para la sociedad y la nación. Las maestras encontraron un espacio público importante para brindar sus saberes permeando de sus conocimientos a la niñez poblana, de tal forma que el aula se volvió un espacio de apropiación, empoderamiento y difusión de sus convicciones, ya que al no existir la uniformidad en el programa se hizo patente la creatividad y el pensamiento personal al momento de ejercer la labor de enseñanza.

Asimismo, cabe preguntarse qué ocurrió con las mujeres que no tuvieron un hombre que hablara por ellas. Es ahí donde se encuentran las voces de las preceptoras, sus saberes y sentires ante las difíciles condiciones sociales y laborales. Rescatando el ejemplo de María Rosa Pérez se puede apreciar a una mujer fuerte que expone ante el gobierno las dificultades con las que realizó su labor de enseñanza, como se testifica en la siguiente declaración:

\begin{abstract}
Ma. Rosa Pérez, mujer de Juan Nepomuceno Salamanca, originaria de esta ciudad, ante la acreditada justificación de V. E. y como mejor proceda Digo: que hace algún tiempo que me he dedicado a enseñanza en primeras letras a cuantas niñas asisten a mi establecimiento de amiga que tengo puesto en la esquina del Parian, gratuitamente mas como la indigencia de mi esposo no le permite auxiliare a causa de sus enfermedades, y deseandole continuar condicho establecimiento en beneficio del público, ocurro a V. E. para que en obsequio de la Juventud desvalida, a la que dispensa su protección en desempeño de sus deberes, se digne auxiliarme con la cantidad que tenga a bien, para el sostén del referido establecimiento. ${ }^{4}$
\end{abstract}

Ante esta petición no se halló que el Ayuntamiento emitiera algún tipo de apoyo o respuesta para aliviar las necesidades de María Rosa Pérez quien antes de demostrar la importancia de su labor, con el propósito de acreditar la seriedad y el compromiso social, lo primero que destaca en su escrito es puntualizar que es habitante de la ciudad y que posee una moralidad respetable al estar casada y declara como parte de la causa de su invalidez los nulos recursos económicos que su esposo aporta al ámbito familiar, mismo que al parecer tiene una extensión con la actividad laboral de María Rosa, pues de acuerdo con sus palabras parece ser que fue a su esposo a quien recurrió primero para sostener el establecimiento de primeras letras y después al Ayuntamiento, a pesar de que la amiga que dirigía era pública y gratuita.

Como se observa, la labor docente sirvió a las maestras como un mecanismo para tener un trabajo remunerado y contribuir al sostenimiento del hogar. Ellas se desempeñaron en el ámbito público y privado, en la educación y en la labor de los servicios necesarios para el sostenimiento del trabajo remunerado y la familia, favoreciendo una doble jornada para las mujeres de escasos recursos realizando la labor proveedora; es decir, el sostén de sus hogares.

${ }^{4}$ AHCMP, Sección: Expedientes, vol. 69, f. 251r. 
Consideremos ahora que tanto hombres como mujeres recurrieron en sus discursos a destacar no sólo su ocupación y experiencia en primeras letras; en muchos casos se observó que sus palabras aludieron a la compasión y el auxilio por parte del gobierno para ser útiles y ejercer una ocupación retribuida, provechosa y digna que en su ámbito personal ayudara a solventar las carencias existentes.

\section{La intervención norteamericana y sus repercusiones (1847-1855)}

Mientras los letrados liberales del siglo XIX establecieron una fe ciega en lo que consideraron el ideal de nación, la sociedad mexicana continuó con sus antiguas estructuras ideológicas. Hasta los años cuarenta de la época decimonónica dichas prácticas siguieron vigentes al constatarse la ficción de la nación. Así, élite letrada, ideología y sociedad permanecieron divididas y su cisma se acrecentó con la invasión de las tropas norteamericanas (Guerra, 1985: 207).

La situación económica del país comenzó a mermar debido a las guerras internas y de intervención extranjera con lo cual la vida cotidiana de los planteles educativos, así como la de los preceptores, se vio afectada en sus finanzas personales al suspenderse el pago de sueldos.

El paso de la intervención norteamericana por Puebla suscitó múltiples conflictos sociales, la inestabilidad pública se hizo palpable y la situación económica se desgastó aún más. Esto significó el cierre de escuelas durante el sitio a la ciudad y fue necesario enviar comunicados departamentales solicitando a los jueces de paz su intervención para auxiliar a la Compañía Lancasteriana a seguir con sus actividades de enseñanza pública. Incluso el mismo Ayuntamiento angelopolitano menciona, a través de su tesorero, que la ocupación norteamericana de la ciudad afectó sus arcas, ya que se perdió el fondo que abastecía diversos ramos entre ellos el educativo; es por ello que solicita a la capital que se le envíen recursos para el pago a los preceptores. ${ }^{5}$

Debido a lo anterior el auge en cuanto al establecimiento de escuelas y la escolarización en masa se vio frenado con la intervención. Las escuelas de la ciudad cerraron debido al sitio estadounidense y posteriormente hubo desconcierto entre los habitantes pues varios planteles no abrieron por la inexistencia de recursos económicos.

La tensa situación social y económica motivó la movilización de los maestros de primeras letras para exigir al Ayuntamiento el pago de sus sueldos. Como mencionan Crozier y Friedberg, "la acción colectiva [...] no son más que soluciones específicas que han creado o instituido

\footnotetext{
${ }^{5}$ AHCMP, Sección: Expedientes, vol. 70, pp. 79r-79v.
} 
actores relativamente autónomos, con sus recursos y capacidades particulares, a los problemas que platea la acción colectiva [...] con miras a cumplir objetivos comunes" (1990: 1).

Lo anterior era con el objetivo de conseguir la retribución de su trabajo, por lo cual los maestros José María Buenhombre, Mariano Cruz, Joel Agustín Gómez, José Bermudez, María de la Luz González y Soledad González unieron fuerzas y de forma grupal solicitaron al Ayuntamiento el pago de los meses de noviembre y diciembre de 1842, para lo cual señalaban: "[...] hoy estrechados ya de la miseria y confiados en que nuestras voces hallarán benévola acogida en esa respetable corporación", y solicitaban ayuda y justicia para solventar las carencias existentes en la educación primaria. ${ }^{6}$

A pesar de la insistencia de los instructores de primeras letras y de que el cabildo encontró certero el adeudo mencionado, el cual ascendía a un total de 686 pesos con dos reales, cifra considerable para la época, no se efectuó el pago por las labores realizadas. Es así que una vez más las malas condiciones laborales motivaron que los preceptores enviaran al Ayuntamiento una nueva carta en la que reiteraban la solicitud del pago de sus salarios y presentaban el panorama general en que se hallaba la instrucción primaria, así también dejaban ver las pasiones que los embargaban:

Excelentísimo Señor. Los preceptores de primeras letras y maestras de amiga que suscribimos ante la notoria justificación de V[uestra] E[xcelencia] con el debido respeto decimos: que cuando nos decidimos a abrazar la penocisima carrera de dar lecciones de primeras letras, a un número indefinitivo de alumnos, que casi en su totalidad pertenecen a la clase más incapas de tratarce, no pudimos hacerlo, sino porque nuestras familias, mas o menos numerosas, nos exigían todo género de sacrificios. Comprometidos con el público, y vigilados por diversas comisiones, era preciso que sacrificaramos a la enseñanza casi todas las horas del día, quedando privados de la oportunidad de buscar un real, para suvenir a las necesidades mas urgentes: asi es, que después de malbaratar los poquísimos intereses que teníamos, capaces de enagenar: de empeñar aún la ropa indispensable para el uso diario, y apurar la paciencia de las personas que nos dispensaron favor, nos hemos visto cargados de deudas, avergonzados por nuestros acredores, y en tal estado de miseria, que mas de una vez no han tomado nuestras familias sino un alimento en el día, ahora infortuna y calidad y cantidad, que sería para un anacoreta correspondiente a los días unos cuanteros [...] nuestros males se hacen cada día mayores, ya nuestros acreedores nos tienen reducidos al rincón más oculto; y aun este no tenemos seguro; y sin amigos, sin dinero, sin sus muebles que enagenar, morimos deudamos de la memoria, que sacrifica a cuantos tienen la desgracia de depender de nosotros. En tan obligadas circunstancias no podemos menos que ocurrir a V[uestra] E[xcelencia] suplicándole que pues en su servicio hemos llegado a tal extremo, aún cuando sea inculpable en no habernos

\footnotetext{
${ }^{6}$ AHGMP, Sección: Expedientes, vol. 70, f. 4lv.
} 
pagado religiosamente nuestros sueldos, se digne mandar que de preferencia se nos acuda a que sea en bonos parciales con los dos mil trescientos setenta y siete pesos que se nos deben desde el mes de Junio hasta el dos de Diciembre en que se nos mandó suspender la enseñanza, y servirán para cubrir compromisos en que el decoro mismo de V[uestra] E[xcelencia], esta empeñado. A V[uestra] E[xcelencia] reiteramos nuestras suplicas que esperamos se dignará atender. Puebla Febrero 14 de 1848. José Bermudez, Josefa María Bermudez, José María González, Soledad Gonzalez, Juan M. Remolina, Catarina Gonzalez, José María Buenhombre, Alvina Oropeza de la Cruz?

La presente carta es invaluable para estudiar a los preceptores decimonónicos, pues en ella narra su sentir respecto a las desfavorables condiciones en que realizaban su labor. En este sentido esgrimían que, desde su perspectiva, la enseñanza de las primeras letras no era un oficio digno de seguir - al menos en el imaginario social poblano- ya que refieren con puntualidad que su labor les daba vergüenza, situación creada por el contexto adverso en el que se desempeñaban. Es palpable que el grado de insatisfacción, el cual se encuentra íntimamente relacionado con la gran cantidad de alumnos que atendían, parece no tener fin y, sobre todo, muestran sus prejuicios ante los pobres y la pobreza en la que viven, arguyendo que en las escuelas públicas se debía tener trato con las personas más bajas y que, a su consideración, eran personas de difícil trato, un pensamiento clasista existente desde la época colonial.

En el escrito se destaca la acción vigía del Ayuntamiento ante la labor de la enseñanza al señalar que se sentían vigilados y, seguramente, intimidados por las diversas comisiones emitidas desde el gobierno, A pesar de no pagar económicamente los servicios prestados, la institución les solicitaba no tener ningún otro tipo de ingreso con otra actividad. Apoyados en el compromiso de servir a la comunidad y cumplir con las demandas de las comisiones, los maestros tenían amplias jornadas laborales que les impedía desempeñar cualquier otra labor en la que recibieran remuneración.

La acción social a la que recurren los preceptores los hace retomar el poder ante la estructura organizativa del Ayuntamiento. Así, "la conducta del subordinado también está en función de las posibilidades de agruparse con sus colegas y de su capacidad para construir relaciones" (Crozier y Friedberg, 1990: 3) con lo cual logra participar en el juego del poder ante instituciones aparentemente estables.

El discurso se centra en relacionar la importancia del oficio y la remuneración correspondiente, creando un lazo de unión entre lo público y lo privado. Es aquí donde las necesidades familiares saltan a la luz, pues la escasez económica se hace factible cuando no hay alimentos que sufraguen las necesidades básicas de los preceptores y sus familias. Incluso, el discurso

\footnotetext{
${ }^{7}$ AHCMP, Sección: Expedientes, vol. 70, f. 4lv..
} 
religioso se hace presente cuando mencionan los sacrificios realizados para solventar sus necesidades más apremiantes.

La desesperación se hace presente a través de las palabras, pues se menciona la necesidad de haber recurrido a préstamos de amigos, familiares, conocidos, prestadores de servicios, empeño de bienes propios, etc., con el propósito de sobrellevar la apremiante situación económica por la que atravesarban.

Para concluir, respecto a esta carta, se muestra que la situación adversa creó solidaridades y lazos de unión entre los preceptores que vivieron penurias muy similares y el Ayuntamiento respondió favorablemente a sus peticiones. Dicha acción propició que otros maestros que abandonaron sus puestos ante la falta de retribución económica también pidieran que se les solventaran las deudas. Tal fue el caso de la maestra de primeras letras María Guadalupe Arce quien cerró la amiga en que laboraba debido a que sólo se le pagaron ocho pesos a lo largo de dos meses y enfatiza que el desempeño en la enseñanza fue arduo y puntilloso con la normatividad impuesta, tanto que cortó con la clientela que había creado mediante sus trabajos de costuras y se halló en la indefensión económica, además de adeudar las rentas del establecimiento, razón por lo que solicitaba que se le pagaran los 70 pesos y medio real adeudados a su cuenta. ${ }^{8}$

Algunos de los nombres que aparecen en la lista no formaron parte de aquellos que se hicieron oír ante el cabildo angelopolitano; sin embargo, también les fue reconocida la deuda que se tenía con ellos y se buscó resarcirla.

Cabe destacar entonces que como afirman Crozier y Friedberg:

Los hombres no se adaptan pasivamente a las circunstancias, sino que son capaces de jugar con ellas. Los actores no son nunca totalmente libres, pero el sistema está igualmente influido, incluso corrompido por las presiones y las manipulaciones de los actores... el hombre... es antes que nada una libertad, o más precisamente un agente autónomo capaz de calcular y de manipular, que se adapta e inventa en función de las circunstancias y de los movimientos de los otros. Por esto, una organización no es un conjunto transparente, sino el reino de las relaciones de poder, de influencia, de regateo y de cálculo (Crozier, Michael y Friedberg, Erhard, 1990: 4).

Por lo tanto, se observa que en México los preceptores se desenvolvieron como actores colectivos que bajo un mismo estandarte -el pago de su dinero- enfrentaron al poder gubernamental, pues notaron que el poder es una relación y no un atributo de cada actor. Por lo que, la elección libre de formar parte de una comunidad disgustada con el Ayuntamiento, forjó lazos que culminaron en derechos y responsabilidades por parte de sus integrantes.

${ }^{8}$ AHGMP, Sección: Expedientes, vol. 70, f. 92r. 
La inestabilidad que trajo consigo la invasión norteamericana se hizo evidente dos años después del conflicto. Hacia 1849 siguen apareciendo en los documentos del Ayuntamiento las cartas de las maestras, a través de las cuales se pueden percibir las irregularidades en su labor y en los pagos. En este caso, la maestra de la amiga perteneciente a la Junta de Caridad y quien laboraba desde 1831 reclamó su pago de 15 pesos mensuales que obtenía de la Junta que, en colaboración con el Ayuntamiento, asignaba para la subsistencia de la preceptora. ${ }^{9}$ Finalmente, el Ayuntamiento liquidó las deudas de los maestros de las escuelas públicas y realizó un informe con los nombres y las partidas de cada preceptor.

La creación de la figura docente en el imaginario del gobierno fue impecable, se convirtió en sinónimo de ciudadano ideal, pues tanto hombres como mujeres no sólo debían demostrar sus conocimientos, sino que también debían acreditar la alta moralidad de sus personas, algo que se consolidó como requisito indispensable para el Ayuntamiento el cual estaba convencido de que sólo un individuo con altos valores sería capaz de enseñar a los demás el talento, los saberes y la adecuada forma de conducirse en una sociedad moderna.

En este sentido, no es de extrañarse que entre las cartas que los preceptores enviaban al Ayuntamiento también se encontraran otros escritos elaborados por algún religioso que, en su carácter de confesor, se convertía en aval de la alta moralidad del solicitante por lo cual enviaba una amplia recomendación a los miembros del gobierno. La importancia de la actividad política de los actores se hace patente en dichos documentos, ya que a través de las cartas de presentación y recomendación se conoce el tipo de instrucción que se saba en la sociedad angelopolitana, sobre todo, cuando se habla de que una década antes no había diferencia entre la actividad del Estado y la Iglesia; por lo contrario, desde la perspectiva que adopta este artículo, eran instituciones que trabajaban juntas en pro del bien social.

\section{La influencia de las Leyes de Reforma en la instrucción pública (1856-1861)}

Las arcas municipales se encontraban en quiebra desde la intervención, y los sitios a la ciudad de Puebla hicieron mella en el sistema educativo público. El cisma se profundizó más cuando la institución que solidificó su proyecto de instrucción durante tres siglos abandonó la maquinaria del progreso. La separación Iglesia-Estado afectó profundamente el mecanismo público educativo, como se muestra a continuación.

Después de la intervención norteamericana el devenir sociopolítico poblano no mejoró. Hacia 1856 se dieron tres sitios debido a la imposición de las leyes de desamortización

\footnotetext{
${ }_{9}^{9}$ AHGMP, Sección: Expedientes, vol. 70, f. 11lr.
} 
eclesiástica y eliminación de fueros religiosos. Todos estos enfrentamientos ocurrieron dentro de la traza urbana y, por supuesto, afectaron la vida cotidiana de los poblanos quienes trataron de seguir adelante ante un panorama de pobreza e incertidumbre laboral y social.

Se llevó entonces a cabo la desacralización del espacio urbano, es decir, mediante las Leyes de Reforma se estableció la desamortización de bienes eclesiásticos y, con ello, una marcada diferenciación entre lo sagrado y lo profano. La intención era formar una cultura cívica entre los nuevos ciudadanos mexicanos, de tal manera que se comenzó por el establecimiento de un panteón nacional y la formación de héroes de bronce que motivaron la consolidación del Estado-Nación.

El delicado lazo entre los poderes civil y religioso se rompió tras la emisión de dichas leyes y, por supuesto, la población angelopolitana reaccionó en defensa de su fe. Tal como ya se mencionó, los últimos sitios se realizaron en apoyo de la religión y el fuero, incluso la Iglesia tuvo que emitir un comunicado, por parte de su obispo Antonio Pelagio quien mediante un impreso pedía a sus feligreses vivir en armonía, sin tumultos, ya que la intención no era atentar en contra de él o de la Iglesia. ${ }^{10}$

En este contexto el Ayuntamiento realizó en 1858 una nueva revisión del gasto público en materia de instrucción de primeras letras que nos permite hacer el seguimiento de las trayectorias académicas de algunos preceptores, debido a que a través del gasto público se registra la continuidad en el oficio, al inscribir en el mismo los nombres de los docentes en servicio.

Al parecer, el único preceptor que tuvo una trayectoria en el oficio fue Mariano Manrique, ya que su nombre aparece en los documentos de 1848 y diez años más tarde sigue figurando entre las listas. Lo anterior muestra que, posiblemente, el mundo de la enseñanza de primeras letras, en su inestabilidad institucional y la constante escasez en cuanto a remuneración económica, vio desfilar una serie de personas que ocuparon el puesto como un oficio más para su subsistencia con lo que difícilmente lograban establecer una trayectoria académica."

Asimismo, cabe la posibilidad de que los maestros hubieran mudado sus residencias fuera de la ciudad y ejercieran su profesión en otros planteles. El apellido Bermúdez, por ejemplo, era ampliamente conocido en el mundo de la enseñanza en Puebla durante el siglo XIX, pero hay dificultad al rastrear a los maestros por su apellido dado que los documentos no mencionan la particularidad del nombre, por tanto, no se sabe con exactitud a cuál de todos los Bermúdez es a quien se hace referencia.

Es también necesario señalar que la fuente de primera mano consultada sólo muestra a aquellos profesores a quienes el Ayuntamiento no pudo pagarles su sueldo, por tanto, es probable que los Bermúdez, al tener ciertas concesiones y encontrarse inmersos en las escuelas de

\footnotetext{
${ }^{10}$ AHGMP, Serie: Leyes y decretos, vol. 17, p. 249r.

${ }^{11}$ AHCMP, Serie: Leyes y decretos, vol. 17, f. 205 r.
} 
la Junta de Caridad y otros puestos de vigilancia educativa, tal vez no tuvieron el problema del pago y por ello sus nombres no aparecen.

Dicho actor social —Bermúdez-, por las relaciones sociales que pudo tejer, que adquirieron mucha fortaleza y privilegiaron su participación en la escena pública, se convirtió entonces en un ejemplar del concepto de experto; es decir, "es el único que sabe hacer las cosas, lo cual permite resolver algunos problemas cruciales para la organización. Su intervención es negociada contra beneficios y privilegios [...] [adquiriendo] un monopolio" (Crozier y Friedberg, 1990: 10).

Por otra parte, las diferencias entre profesores se hacían evidentes, pues mientras los maestros nocturnos sólo daban clases por un lapso de hora y media a un número escaso de alumnos, los diurnos de las escuelas masculinas y femeninas dedicaban la mayor parte del día a su labor de enseñanza con aulas repletas de alumnos. A pesar del contraste de horas trabajadas ambos recibían igual sueldo, cuando su labor por lo que toca a horas invertidas era inequitativa a todas luces. Mientras los nocturnos lograban empatar dos trabajos a los diurnos se les exigía dedicación exclusiva, incluso, cuando no había dinero en las arcas del Ayuntamiento eran los segundos quienes siempre se quedaban sin pago alguno.

\section{La significativa presencia de la familia Bermúdez}

Reconstruir las biografías de los maestros del siglo XIX es una tarea ardua, puesto que son escasos los rastros de sus vidas en un mar de documentación pública que difícilmente puede brindar un seguimiento de su vida o su trayectoria académica, sin embargo, algunos documentos brindan esbozos entre los cuales el historiador puede intentar realizar un trabajo de tal magnitud.

Las sociedades tradicionales buscaban crear lazos a través del primer grupo básico de la sociedad: la célula familiar, contando con el parentesco como la primera relación surgida de un grupo original basado en la relación de sangre o en alguna alianza matrimonial. Así, "tienen en la mayoría de los casos la fuerza de lazos afectivos intensos, y se refuerzan por la comunidad de intereses, pues los miembros de la familia son a menudo solidarios tanto en el éxito como en el fracaso" (Guerra, 1985: 128). Además, cuentan con generaciones jóvenes que suceden a las que van envejeciendo, lo que convierte a la célula familiar en un actor inmortal que delega en las generaciones futuras el éxito social, a través de la red de relaciones tejidas desde décadas anteriores.

En la escala de valores de la sociedad los lazos que unen a la familia son considerados superiores a cualquier otro y es necesario añadir que al parentesco de sangre también se suman el político, el espiritual y el de compadrazgo, mismos que se ven reflejados en dicha unidad social. En este caso, el apellido Bermúdez es un apellido singular que aparece a lo largo de 
diversos documentos. Esto nos motivó para intentar reconstruir lo que se piensa como un pasado familiar en la historia de la instrucción poblana, a partir de diversas fuentes bibliográficas y de archivo donde podemos observar la vida del actor colectivo familiar.

El primer rastreo mostró que Ángel Bermúdez fue el primero en aparecer en la escena decimonónica, ya que es él quien en 1814 se convirtió en el preceptor de la Escuela de Escribir que llevó a cabo la Junta de Caridad. Logró obtener el puesto gracias a su impecable informe de vida, costumbres, limpieza de sangre y buenas disposiciones. Su labor como maestro en dicha escuela continuó hasta 1831. Asimismo, la Escuela de Leer fue llevada a cabo por la Junta bajo los mismos requerimientos y le fue encargada, de 1818 a 1831, a José Mariano Bermúdez, pariente de Ángel Bermúdez (Rosales, 2008: 59-60).

Existe un documento que muestra cierta trascendencia de la vida de Ángel, pues se menciona su participación en los espacios religiosos lo cual — seguramente—-fungió como carta de recomendación para destacar su amplia moralidad, virtudes y compromiso con el clero por su desempeño como mayordomo y tesorero de la archicofradía del Señor de la Expiración, fundada en la iglesia de San Juan de Letrán y colegios de niñas vírgenes de la Purísima Concepción y San José de Gracia de la ciudad de Puebla. ${ }^{12}$ Se muestra entonces que tanto Ángel como José Mariano entraron en el gremio mediante los estándares establecidos en el periodo colonial el cual, a pesar de los cambios realizados en la legislación influenciada por el movimiento de independencia, seguramente continuó dentro del imaginario novohispano.

Los expedientes hallados en el Ayuntamiento referentes a apoyos para la enseñanza de primeras letras muestran a un tercer pariente: José María Bermúdez, preceptor de la Escuela Gratuita ubicada en el barrio de San Antonio, quien realizó las gestiones propicias para que su hija Josefa Bermúdez ingresara en el mundo de la enseñanza de primeras letras, logrando el establecimiento de la amiga en una casa del mismo barrio.

La actividad política y administrativa de José María Bermúdez como preceptor del barrio de San Antonio fue notable en la ciudad de Puebla, debido a que su reglamento de escuela fue instaurado en las demás escuelas públicas y también a que se convirtió en la cabeza del grupo de profesores examinadores de las maestras de primeras letras que consideraban acceder a cualquier establecimiento público. El nombre de José María Bermúdez aparece nuevamente en el grupo de maestros que solicita al Ayuntamiento enérgicamente su pago en 1848, acción que nuevamente resultó exitosa.

Diez años más tarde (1858) el nombre de José Bermúdez aparece, nuevamente, en la lista de los preceptores encargados de las escuelas diurnas de primeras letras; incluso su hija continuó en el cargo solicitado para ella desde 1830 y surgen en escena dos nuevos nombres:

\footnotetext{
${ }^{12}$ BJML-BUAP, Sección: Escuela de Artes y Oficios, caja 52, exp. 2, sin número de folio.
} 
Mateo y Mariano Bermúdez, preceptores encargados de dos escuelas nocturnas para la enseñanza de primeras letras.

En una carta de 1862 la preceptora María Inés Manjarrés se queja de haber sido víctima de un fraude orquestado por Mariano Bermúdez a quien ahora se le menciona como inspector de escuelas y, a pesar de que no se halló un documento que diera fe del postulado, el Ayuntamiento nunca se preocupó por desmentir tal aseveración, por tanto, se da por cierto el comentario de Inés..$^{13}$

No podemos saber si el referido Mariano es el mismo que era nombrado como José Mariano quien en un principio fue preceptor de la escuela a cargo de la Junta de Caridad. Pero atendiendo a la precisión de los nombres esto indica que se trata de dos personajes distintos y que el primero - Mariano Bermúdez - escaló de las escuelas nocturnas a inspector de planteles, afirmaciones que se realizan a partir de algunos documentos hallados en el Archivo Municipal.

\section{Notas finales}

La historia de la educación en Puebla presenta una serie de retos que se deben subsanar. En primer lugar el hecho evidente de la necesidad de reconstruir las biografías de los preceptores de primeras letras quienes dejaron su legado a partir de los conceptos que sembraron en sus alumnos durante su paso por las escuelas públicas de la ciudad. En segundo lugar, además de atender dicha demanda se favorecería una reconstrucción de los saberes docentes donde no sólo se conocerían los métodos de selección, sino que se profundizaría en la formación de preceptores de primeras letras, los cuales tuvieron mayor influencia en la población al impactar en el amplio espectro de la educación básica, cosa que no lograron los estudios profesionales.

La injerencia del clero poblano en la formación de la niñez fue amplia, ya que se dio a través de los espacios de poder que ocupó el cabildo angelopolitano para realizar los criterios de selección de los preceptores, siendo evidente que sus miembros más allegados obtuvieron plazas mejor remuneradas o de mayores incentivos económicos por parte del Ayuntamiento.

Es necesario recalcar que uno de los requisitos en el proceso de selección de los candidatos a ocupar las plazas otorgadas por el Ayuntamiento para los preceptores de primeras letras era la presentación de una carta que demostrara la moralidad de los hombres y mujeres que desearan ingresar a la instrucción pública. En general, dicha carta era expedida únicamente por sacerdotes que aprobaban la rectitud del solicitante, o por particulares

\footnotetext{
${ }^{13}$ AHGMP, Sección: Expedientes, vol. 71, f. 85r.
} 
reconocidos socialmente por su calidad moral, mismos que también debían ser avalados por el clero. Por ello la Iglesia fue un actor importante en las normas que más tarde aprobaría y reconocería el Ayuntamiento como características deseables en sus ciudadanos empezando por sus preceptores modelos de la infancia.

Aunado a lo anterior, la participación eclesiástica estaba implícita en el anquilosado imaginario social, pues los preceptores de primeras letras que enseñaron en la primera mitad del siglo XIX cargaban con el peso de los conocimientos novohispanos que arraigadamente estableció la actividad pastoral creada y difundida por la Iglesia poblana. Además de que los valores y principios éticos al estar relacionados con los conceptos morales de la época se basaron en las premisas que estableció y aprobó la mitra para demostrar la buena conducta de los individuos.

\section{Fuentes}

Archivos

Archivo Histórico General Municipal de Puebla (AHCMP), Puebla, Pue., Fondo: Expedientes, vols. 69, 70 y 71.

Biblioteca Antigua José María Lafragua-BUAP (BJML), Puebla, Pue., Fondo: Escuela de Artes y Oficios, caja 52.

Bibliografía

Becerril, Roberto (2013), "La política ilustrada y el financiamiento educativo. Más continuidad que ruptura", en Alicia Civera Cerecedo (coord.), Experiencias educativas en México, un recorrido histórico,

El Colegio Mexiquense, A. C., Fondo Editorial del Estado de México, México.

COMIE (Comité Mexicano de Investigación Educativa) (2003), La investigación educativa en México, SEP, CESU, México.

Crozier, Michael y Erhard Friedberg, (1990), El actor y el sistema. Las restricciones de la acción colectiva, Alianza Editorial Mexicana, México.

Guerra, Francois Xavier (1985), México: del antiguo régimen a la revolución, FCE, México.

Herrera, Lourdes (2007), "La infancia asilada en las instituciones de asistencia pública en Puebla durante la segunda mitad del siglo XIX", en María de Lourdes Herrera Feria (coord.), Estudios sociales sobre la infancia en México, BUAP, Puebla.

(2012a), "Frágiles y desamparados: mujeres y niños en la ciudad de Puebla", en Carlos Contreras y Miguel Ángel Cuenya (coord.), Puebla. Historia de una identidad regional, vol. 2, Siglo XIX. De la lucha por la soberanía nacional a la modernidad porfiriana, Milenio, México.

Herrera, Lourdes (2012b), "Panorama de la instrucción elemental en la ciudad de Puebla durante el siglo XIX", en Carlos Contreras y Miguel Ángel Cuenya (coords.), Puebla. Historia de una identidad regional, vol. 2, Siglo XIx. De la lucha por la soberanía nacional a la modernidad porfiriana, Milenio, México.

(2015), "La fundación del hospicio de pobres en la Puebla de los Ángeles, 1771-1832", Revista Mexicana de Historia de la Educación, vol. 3, núm. 5, enero-junio, México, pp. 69-96.

Márquez, Jesús (2004), Historia social y cultural de la educación. Trayectoria y notas para su estudio en Puebla, BUAP, México. 
Márquez, Jesús (2012), La obscura llama, élites letradas, política y educación en Puebla 1750-1835, Educación y cultura-BUAP, México.

Munguía, Estela (2010), Puebla, algunos capítulos de su historia educativa. De la independencia a la revolución, Educación y cultura-BUAP, México.

Neve, Mariana (2009), La construcción de los saberes pedagógicos del magisterio poblano durante el Porfiriato, tesis de licenciatura en Historia, BUAP, Puebla.

Pineau, Pablo (1999), "Premisas básicas de la escolarización como construcción moderna que construyó la modernidad", Revista de Estudios del Currículum, Editorial Palomares, Barcelona, pp. 39-61.

Popkewitz, Thomas S. (1998), La conquista del alma infantil. Política de escolarización y construcción del nuevo docente, UNAM, México.

Rosales, Mónica Alejandra (2008), La Junta de Caridad y Sociedad Patriótica para la Buena Educación de la Juventud. Puebla 1813-1829, tesis de licenciatura en Historia, BUAP, Puebla.

Rodríguez, Lucero (2014), La irrupción del libro en la educación de niñas y la apertura de amigas gratuitas en la ciudad de Puebla, t de maestría en Historia, BUAP, México.

Tanck de Estrada, Dorothy (2005), La educación ilustrada 1786-1836, El Colegio de México, México. (coord.) (2011), Historia mínima ilustrada de la educación en México, El Colegio de México, México.

Torres, Rosario (2014), "La enseñanza de primeras letras a las niñas de Puebla, un estudio a partir de sus reglamentos 1790-1843", Revista Mexicana de Historia de la Educación, vol. II, núm. 4, julio-diciembre, pp. 223-242.

Mariana Marín Ibarra es estudiante del doctorado en Educación en la Universidad Autónoma de Tlaxcala. Sus líneas de investigación son historia de las mujeres e historia de la educación pública. Entre sus publicaciones recientes se encuentran: "Voces ocultas. Las preceptoras poblanas de primeras letras en el siglo XIX", Variedad y diversidad. Acercamientos a los trabajos, actividades y condiciones de las mujeres en México, siglos XIx y XX. Gloria A. Tirado Villegas y Elva Rivera Gómez (coords.), BuAP, México, 2017, pp. 39-50; "Una laudable ocupación: la enseñanza de primeras letras en la ciudad de Puebla en 1863", El Pregonero [revista digital], Archivo Histórico del Ayuntamiento de Puebla, 2016, pp. 4-6; "Visibilizar a las poblanas del siglo XIX. Vacíos y retos en los estudios históricos", Seguir las huellas. Hacia el primer centenario del primer congreso feminista, BUAP, México, 2015, pp. 31-46; y "Educación, el discurso de la modernidad", Memorias del Congreso Internacional e Educación, Universidad Autónoma de Tlaxcala, México, núm. A 052, 2015.

Recibido: 9 de mayo de 2017.

Aceptado: 18 de septiembre de 2017. 